
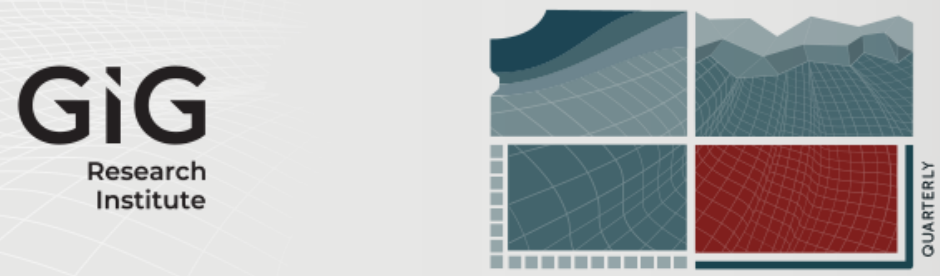

JOURNAL

OF

SUSTAINABLE

MINING

\title{
A lab study of mineral scale buildup on line and traditional PE water pipes for acid mine drainage
}

Author(s) ORCID Identifier:

Amanda Pezzuto (iD 0000-0002-8192-1885

Emily Sarver (D) 0000-0003-2301-8740

Follow this and additional works at: https://jsm.gig.eu/journal-of-sustainable-mining

Part of the Explosives Engineering Commons, Oil, Gas, and Energy Commons, and the Sustainability Commons

\section{Recommended Citation}

Pezzuto, Amanda and Sarver, Emily (2020) "A lab study of mineral scale buildup on line and traditional PE water pipes for acid mine drainage," Journal of Sustainable Mining: Vol. 19 : Iss. 1 , Article 5.

Available at: https://doi.org/10.46873/2300-3960.1004

This Research Article is brought to you for free and open access by Journal of Sustainable Mining. It has been accepted for inclusion in Journal of Sustainable Mining by an authorized editor of Journal of Sustainable Mining. 


\title{
A lab study of mineral scale buildup on line and traditional PE water pipes for acid mine drainage
}

\begin{abstract}
Plastic, especially polyethylene (PE), pipe material is increasingly used in mining applications due to its inert nature, flexibility, low density, and low cost. Though resistant to chemical corrosion, it is susceptible to abrasion. To combat this problem, an abrasion-resistant liner is in development. However, it is not yet known how the liner will perform with regards to other common problems that affect pipe systems, such as mineral scale buildup. In mining applications, scale buildup occurs due to the very high contents of suspended and dissolved solids in water or slurry. For example, in systems transporting raw or treated acid mine drainage (AMD), scale can form on pipe surfaces due to sedimentation or the diffusion of particles onto the surface, or precipitation of solids directly onto the surface. In this study, pipe-loop experiments were conducted in the laboratory under three idealized AMD treatment scenarios (i.e., untreated, passively treated and actively treated) to compare mineral scale buildup on traditional versus lined PE pipe materials.
\end{abstract}

\section{Keywords}

Mineral scale; Water conveyance; Water pipes; Acid mine drainage

\section{Creative Commons License}

(c) (i)

This work is licensed under a Creative Commons Attribution 4.0 License. 


\title{
A lab study of mineral scale buildup on lined and traditional PE water pipes for acid mine drainage treatment applications
}

\author{
Amanda Pezzuto, Emily Sarver*
}

Virginia Tech, Blacksburg, VA, USA

\begin{abstract}
Plastic, especially polyethylene (PE), pipe material is increasingly used in mining applications due to its inert nature, flexibility, low density, and low cost. Though resistant to chemical corrosion, it is susceptible to abrasion. To combat this problem, an abrasion-resistant liner is in development. However, it is not yet known how the liner will perform with regards to other common problems that affect pipe systems, such as mineral scale buildup. In mining applications, scale buildup occurs due to the very high contents of suspended and dissolved solids in water or slurry. For example, in systems transporting raw or treated acid mine drainage (AMD), scale can form on pipe surfaces due to sedimentation or the diffusion of particles onto the surface, or precipitation of solids directly onto the surface. In this study, pipe-loop experiments were conducted in the laboratory under three idealized AMD treatment scenarios (i.e., untreated, passively treated and actively treated) to compare mineral scale buildup on traditional versus lined PE pipe materials.
\end{abstract}

Keywords: mineral scale, water conveyance, water pipes, acid mine drainage

\section{Introduction}

$\mathrm{M}$ ine influenced water (MIW) is ubiquitous on and around many mining and milling sites. This term is used broadly to refer to any water that has been affected by mining activities, even just by being in contact with newly exposed geologic materials (e.g., through runoff, seepage from stockpiles, pit or underground mine dewatering) [1]. MIW can additionally refer to those waters reclaimed from productive use on site (e.g., slurried material transport, mineral processing applications). Whatever the source, MIW must often be captured and treated before discharge or (re)use. This requires careful design, operation and maintenance of special systems, which can include expansive pipe networks for water conveyance. Due to MIW quality, operating parameters and environmental conditions, pipe wear and stress can occur via a range of mechanisms such as internal abrasion, corrosion, or mineral scale buildup and external degradation due to UV light exposure, freeze-thaw cycles or pressure loading (e.g., for buried pipes or those in high traffic areas) (e.g. [2-4]). Any of these factors, or combinations thereof, can lead to immediate or gradual pipe failures (e.g. [2,3]).

One of the most common MIW qualities is that which arises from acid mine drainage (AMD). AMD is primarily caused by the oxidation of exposed sulfide minerals, such as pyrite [5]. These minerals commonly occur within and around metal and coal deposits but may also be associated with other mined mineral deposits. Rock breakage and comminution, which are fundamental to mining and milling operations, significantly increase the available surface area of geologic materials that can readily react with air and water, thereby accelerating the oxidation process [6]. In extreme cases, AMD can result in $\mathrm{pH}$ conditions as low as -3.5 [7]. Additionally, acid mine drainage and associated

Received 15 May 2019; revised 3 December 2019; accepted 8 January 2020.

Available online 5 October 2020

* Corresponding author.

E-mail address: esarver@vt.edu (E. Sarver). 
MIW often exhibit elevated concentrations of metals (e.g., manganese, aluminum, iron), silicates, and other inorganic ions due to the ability of acidic waters to dissolve surrounding minerals [6]. In the case that the acid mine drainage meets surrounding surface waters, impacts on aquatic ecosystems can be significant (e.g., [7-12]). Moreover, AMD can also create problems on-site for mining operations, including those associated with the degradation of highwalls, slopes or embankments or the accelerated corrosion of equipment, roof support, etc. (e.g., [13]).

Because of the broad range of potential impacts, both on site and to the surrounding ecosystems, it is critical to identify AMD generation potential and mitigate it through prevention or treatment. Both active and passive treatment schemes for AMD are common. Active treatment generally entails the addition of soluble neutralization agents, such as calcium oxide in a managed facility [14]. The benefits of such treatment include its effectiveness in treating a wide variety of severe water conditions, relatively small space requirements, and short treatment times [14]. However, active treatment systems can be energy and cost intensive due to mechanical requirements (i.e., pumps, mixers), capital investments and chemical supplies [15].

In contrast, passive treatment typically involves allowing solid carbonate (e.g., limestone or dolomite) to dissolve into the affected water in a flow through system designed with an adequate reaction time [16]. Limestone ponds or drains are a common design scheme [16]. The main benefit of passive treatment is that the process is less intensive in terms of costs and energy [16,17]. However, passive systems are normally only practical in lower acidity scenarios, where metal concentrations are also relatively low [18].

In either treatment scenario, acid neutralization and the associated increase in $\mathrm{pH}$ often leads to the precipitation of metals, often as hydroxides [19]. In some cases, precipitation is desirable because it enables the removal of excess metals [4]. Though typical passive treatments tend to self-buffer near neutral $\mathrm{pH}$, active treatments can be used to attain higher $\mathrm{pHs}$ [20]. As $\mathrm{pH}$ increases the precipitated minerals can lead to buildup on surfaces such as pipes and pumps used for conveying AMD, which is undesirable [21,22]. This buildup is frequently referred to as "pipe scale".

Scale can accumulate either due to precipitation of solids directly onto the surfaces, or by the settling/ diffusion of solids to the surfaces. Excess pipe scale can restrict flow and result in pump failures, and in some cases it can cause actual pipe failure (i.e., leaks or bursts). Such outcomes can have significant financial impacts, and potentially pose environmental hazards. Inert pipe materials, such as plastics, generally lead to less scale buildup than most metal materials, but they are subject to other problems such as abrasion.

To reduce abrasion effects, a number of materials have been tried and tested in the mining environment [23]. Recently, internally lined plastic pipes (e.g., with a synthetic rubber) have been considered for use in mining applications. However, the relative susceptibility of such liners to scale buildup is not well characterized. In a preliminary investigation by the authors [24], a lined polyethylene (PE) pipe product from Gerodur MPM Kunststoffverarbeitung $\mathrm{GmbH}$ and Co. KG. (Gerodur) was briefly field-tested in the Reiche Zeche mine in Freiberg, Germany. This is a historic underground metal mine, where AMD occurs with varying severity in different locations. The results generally indicated that the lined pipe was no more susceptible to scale buildup than its traditional (unlined) counterpart, though the testing was of limited duration and exposure conditions only included untreated AMD.

To follow-up on the preliminary field study, a laboratory study has been conducted and is presented in this paper. This study consisted of pipeloop experiments to examine scale buildup on the same lined and traditional PE pipe products in three idealized AMD conditions: untreated, passively treated, and actively treated AMD. Pipe-loops have been established as a reliable way to test the performance of piping materials under realistic flow conditions (). Here, scale buildup was evaluated on the pipe material samples exposed to constant flow within the loops, and also on samples mounted to the side (minimal flow and mixing conditions) and bottom (subject to gentle flow and water mixing) of the pipe-loop reservoirs.

\section{Materials and methods}

\subsection{Experimental apparatus}

To conduct the experiments, three reservoirs $(57 \mathrm{~L})$ were used, each having a water quality designed to simulate a different AMD treatment condition (see below). Each reservoir fed two pipeloops (i.e., one to expose lined PE samples and the other to expose traditional PE samples). The loops were constructed using $64 \mathrm{~cm}$ lengths of rigid acrylic tube ( $2.54 \mathrm{~cm}$ diameter) with vinyl tubing on either end to complete the flow path to and from the reservoir (Fig. 1). Six identical submersible pumps were used with flow rates of $7.6 \pm 0.1 \mathrm{~L} / \mathrm{min}$; this 


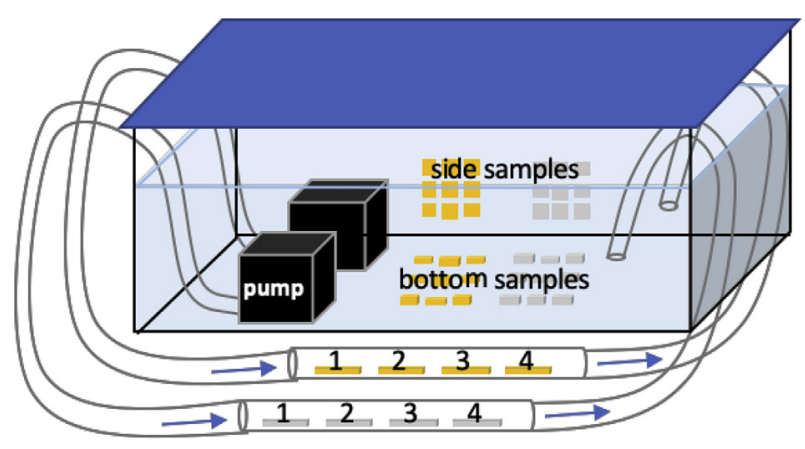

Fig. 1. Schematic of test reservoirs. Each reservoir had two recirculating pipe-loops (flow direction shown by arrows). Four lined (grey) or traditional PE pipe material (yellow) samples were mounted in series within a rigid section of each loop. Nine samples of each material were also mounted to the side and to the bottom of the reservoir.

provided turbulent flow through the tubes (a Reynold's number of approximately 7000). Stir plates were placed underneath each reservoir to ensure that the water remained well mixed, though mixing was gentle.

Lined and traditional PE material samples were prepared for testing utilizing $10 \mathrm{~cm}$ diameter pipes provided by Gerodur. The pipes were cut into approximately $1 \mathrm{~cm}$ by $1 \mathrm{~cm}$ squares; at this size, the samples were nearly flat (i.e., they had very little curvature). In addition, wall thickness was sanded from the outside to accommodate the size of the pipe-loop tube. The samples were exposed in three different locations in each reservoir as shown in Fig. 1: within the pipe-loop "tube", on the "bottom" of the reservoir, and on the "side" of the reservoir.
At the beginning of the experiments, four samples were placed inside each acrylic tube section (see Fig. 1). For this, the samples were mounted onto nylon ties, which were then adhered to the bottom of the tube. Mounting the samples like this allowed them to be removed during water changes, so as to minimize physical and chemical disturbance of any precipitates forming on the sample surfaces. Additionally, nine samples of each material type were located on the side and on the bottom of each reservoir. These samples were mounted onto brass wire mesh before being placed in their respective testing locations, again to allow easy removal during water changes. It is noted that the mesh was observed to corrode over the course of the experiments, particularly in Reservoir 1, which had the lowest $\mathrm{pH}$. This contributed some zinc to the test water and scale build-up on samples.

\subsection{Water qualities}

To simulate different treatment conditions for AMD (i.e., untreated, passively treated and actively treated), three water qualities were tested: Reservoir 1 (untreated AMD) had $\mathrm{pH}$ 4.5, Reservoir 2 (passively treated AMD) had $\mathrm{pH} 6.5$, and Reservoir 3 (actively treated AMD) had $\mathrm{pH}$ 8.5. All waters had the same initial target concentrations (Table 1) for iron (dosed as $\mathrm{Fe}_{2}\left(\mathrm{SO}_{4}\right)_{3}$ ), aluminum (dosed as $\left.\mathrm{Al}_{2}\left(\mathrm{SO}_{4}\right)_{3}\right)$, silicon (dosed as $\mathrm{Na}_{2} \mathrm{SiO}_{3} \cdot 9 \mathrm{H}_{2} \mathrm{O}$ ), calcium (dosed as $\mathrm{CaCO}_{3}$ and $\mathrm{CaSO}_{4} \cdot 2 \mathrm{H}_{2} \mathrm{O}$ ) magnesium (dosed as $\mathrm{MgSO}_{4} \cdot 7 \mathrm{H}_{2} \mathrm{O}$ ), and sulfate (balance

Table 1. Average elemental concentrations (in $\mathrm{mg} / \mathrm{L}$ ) for the first 8 weeks of pipe-loop experiments as measured by ICP-MS. The method reporting limit $(M R L)$ for all elements included here is at least 100 times lower than any reported value, based on calibration data generated from a series of standard solutions analyzed at the beginning of each ICP-MS instrument run. (Note that zinc was not dosed to any of the reservoirs, but was determined to be slowly dissolving from the wire mesh used to mount the pipe samples to the side and bottom of the reservoirs.)

\begin{tabular}{|c|c|c|c|c|c|c|c|}
\hline \multirow{3}{*}{\multicolumn{2}{|c|}{$\begin{array}{l}\text { Element } \\
\text { (target conc. in mg/ } \\
\text { L) }\end{array}$}} & \multirow{2}{*}{\multicolumn{2}{|c|}{$\frac{\text { Reservoir } 1}{\mathrm{pH} 4.5}$}} & \multirow{2}{*}{\multicolumn{2}{|c|}{$\frac{\text { Reservoir } 2}{\mathrm{pH} 6.5}$}} & \multirow{2}{*}{\multicolumn{2}{|c|}{$\frac{\text { Reservoir } 3}{\mathrm{pH} 8.5}$}} \\
\hline & & & & & & & \\
\hline & & \multirow{2}{*}{$\frac{\text { Unfiltered }}{12.4}$} & \multirow{2}{*}{$\frac{\text { Filtered }}{1.9}$} & \multirow{2}{*}{$\begin{array}{l}\text { Unfiltered } \\
10.7\end{array}$} & \multirow{2}{*}{$\frac{\text { Filtered }}{0.1}$} & \multirow{2}{*}{$\begin{array}{l}\text { Unfiltered } \\
9.9\end{array}$} & \multirow{2}{*}{$\frac{\text { Filtered }}{0.8}$} \\
\hline $\mathrm{Al}$ & fresh & & & & & & \\
\hline (10) & aged & 6 & 0.2 & 6.4 & 0.1 & 9.1 & 0.3 \\
\hline $\mathrm{Ca}$ & fresh & 373 & 376.2 & 447.1 & 406.1 & 468.3 & 377.9 \\
\hline (100) & aged & 407 & 413 & 441.4 & 416.6 & 515.7 & 403.2 \\
\hline $\mathrm{Fe}$ & fresh & 24.9 & 0.1 & 20.6 & 0.1 & 18.3 & 0.1 \\
\hline (20) & aged & 14.1 & 0.1 & 13 & 0.1 & 16.7 & 0.2 \\
\hline $\mathrm{Mg}$ & fresh & 5.8 & 5.9 & 5.9 & 5.8 & 5.5 & 4.4 \\
\hline (10) & aged & 6 & 6.1 & 5.9 & 5.9 & 6 & 5.2 \\
\hline $\mathrm{Na}$ & fresh & 29.1 & 30.2 & 27.7 & 28.8 & 26.2 & 27.5 \\
\hline (30) & aged & 30.1 & 31.3 & 28.4 & 29.8 & 27.8 & 28.8 \\
\hline $\mathrm{SO}_{4}$ & fresh & 960 & 998.1 & 872.3 & 941.3 & 863 & 959.9 \\
\hline (1000) & aged & 1019.9 & 1084.1 & 902 & 986.3 & 904.1 & 953.5 \\
\hline Si & fresh & 14.4 & 11.7 & 13.6 & 5.7 & 12.1 & 3.5 \\
\hline (15) & aged & 10.6 & 8 & 9.6 & 4.3 & 11.5 & 2.8 \\
\hline \multirow[t]{2}{*}{$Z n$} & fresh & 4.7 & 4.7 & 2.5 & 0.3 & 0.8 & $<0.1$ \\
\hline & aged & 28.4 & 26.6 & 5 & 0.9 & 4.4 & 0.5 \\
\hline
\end{tabular}




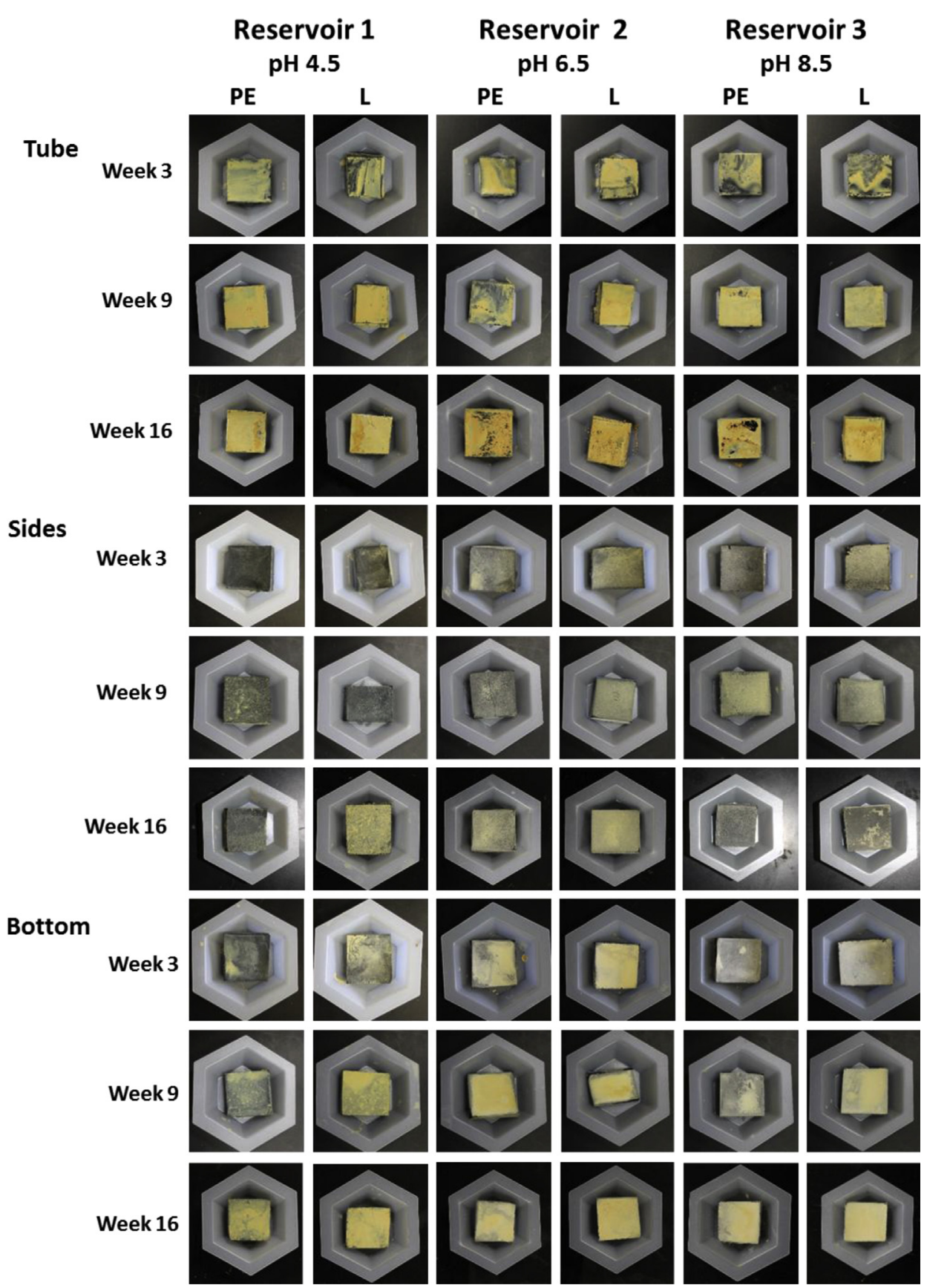

Fig. 2. Photographs of scale buildup in each reservoir at three, nine and 16 weeks of exposure.

was added $\mathrm{H}_{2} \mathrm{SO}_{4}$ ). The initial $\mathrm{pH}$ was adjusted to the target value with either concentrated $\mathrm{H}_{2} \mathrm{SO}_{4}$ or $\mathrm{Ca}(\mathrm{OH})_{2}$.

For the first week, water in all three reservoirs was tested every day to establish how quickly it was changing; in addition to measuring $\mathrm{pH}$, concentrations of dissolved aluminum, iron, sulfates, and alkalinity were measured using a Hach DR 2800 spectrophotometer (Loveland, CO). During the second week, $\mathrm{pH}$, sulfates, and alkalinity were measured every day, and the remaining parameters were measured every three days. After two weeks, aluminum, iron, and calcium concentrations had decreased significantly, and so it was decided that water changes should be conducted once every two weeks. Water changes were conducted using a simple dump-and-fill procedure.

Before and after each water change, inductively coupled plasma-mass spectroscopy (ICP-MS; Thermo Electron $X$ Series, Waltham, MA) was used to measure the suite of elements shown in (Table 1). For this, both total and filtered water samples were 


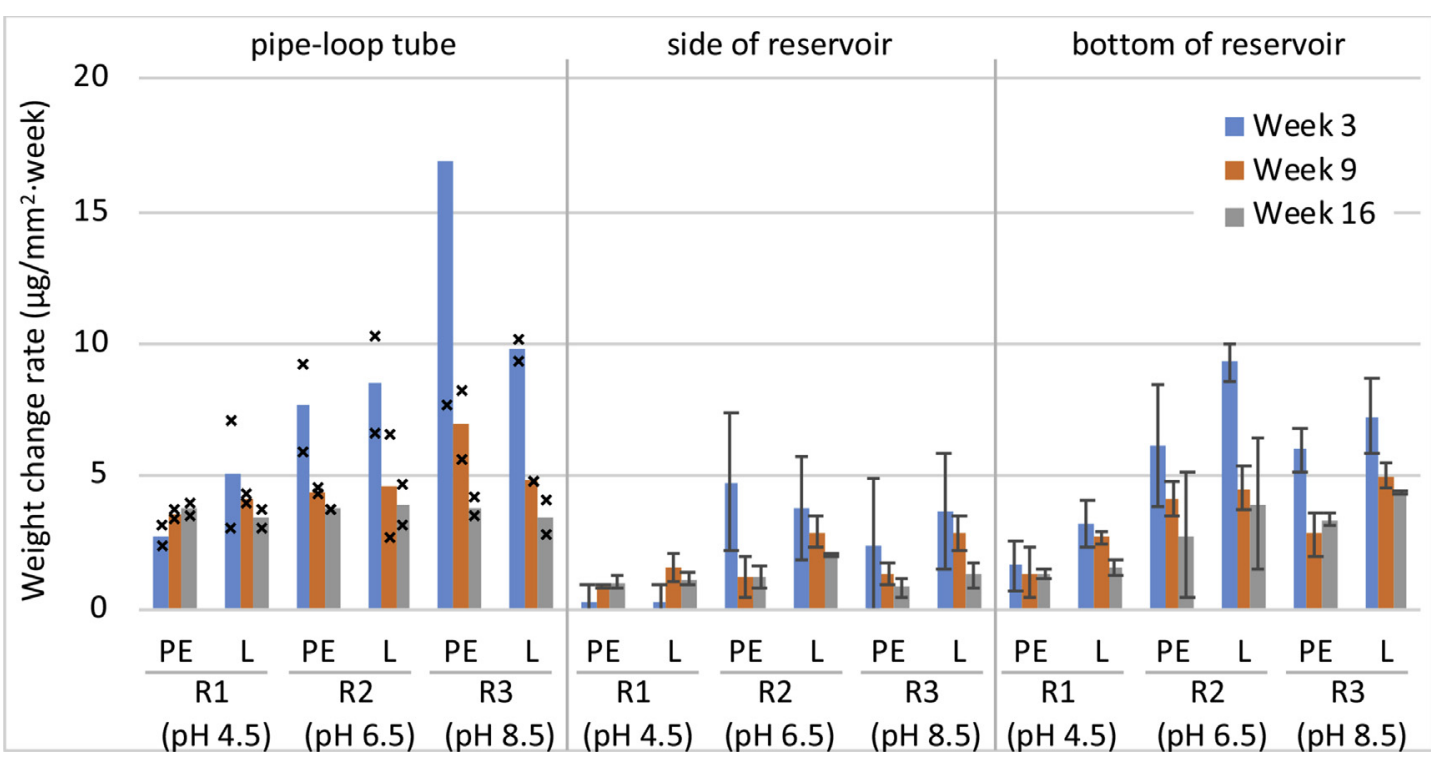

Fig. 3. The normalized rate of weight gain on lined $(L)$ and traditional PE material samples for samples mounted within the pipe-loop tubing (left), on the side (middle), and on the bottom (right) of each reservoir. Results are show for three, nine and 16 weeks of exposure. For side and bottom samples, results are shown as the average of triplicate samples and error bars represent $95 \%$ confidence limit. For samples exposed in the pipe-loop tubing, results are shown as an average of the two samples weighed at each exposure time (i.e., the first and last sample in the flow series) and the " $x$ " markers represent the actual values for those two samples.

collected to determine total and soluble elements. The $\mathrm{pH}$ in each reservoir was measured, and adjusted if necessary, every three days; values were generally maintained within $0.5 \mathrm{pH}$ units. This only minimally impacted the total sulfate and calcium (Table 1).

\subsection{Analysis of scale buildup}

From each reservoir, three bottom and side samples of each material were taken at the end of three weeks, three more samples were taken at nine weeks, and the final samples were taken at 16 weeks. Following retrieval, the samples were analyzed for weight gain, surface morphology, and elemental composition. At the same time intervals, the first and last samples were also removed from each pipe-loop and weighed. Then, the first sample was placed back in its respective tube for continued exposure; and the last sample was analyzed for surface morphology and elemental composition. Analysis of the tube samples was done this way to

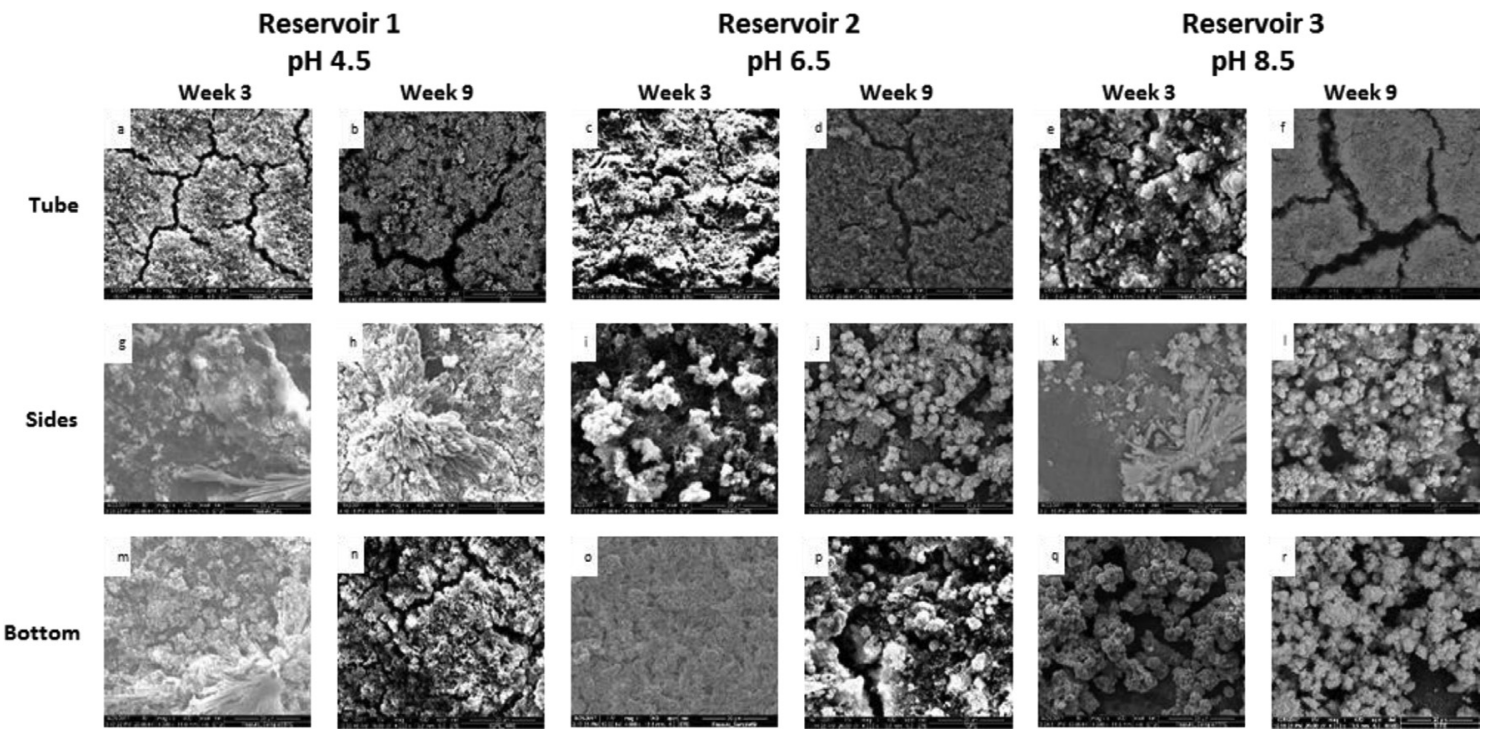

Fig. 4. Representative SEM images for samples from each reservoir and sample exposure location at three and nine weeks of exposure. All images were captured at $4000 x$ magnification. 
Table 2. Summary of major chemical constituents (atomic \%) observed in mineral scales based on SEM-EDX analysis.

\begin{tabular}{|c|c|c|c|c|c|c|}
\hline Reservoir & $\begin{array}{l}\text { Pipe-loop } \\
\text { Tubing }\end{array}$ & & Side & & Bottom & \\
\hline \multirow[t]{6}{*}{1} & $\sim 20 \%$ & $\mathrm{Fe}$ & $\sim 20 \%$ & $\mathrm{Fe}$ & $\sim 20 \%$ & $\mathrm{Fe}$ \\
\hline & $9-10 \%$ & $\mathrm{Al}$ & $9-10 \%$ & $\mathrm{Al}$ & $9-10 \%$ & $\mathrm{Al}$ \\
\hline & $4-5 \%$ & $\mathrm{Si}$ & $5 \%$ & $\mathrm{Si}$ & $5 \%$ & $\mathrm{Si}$ \\
\hline & $2-3 \%$ & $S$ & $3-4 \%$ & S & $3-4 \%$ & $S$ \\
\hline & $\sim 0.5 \%$ & $\mathrm{Ca}$ & $0 \%$ & $\mathrm{Ca}$ & $0 \%$ & $\mathrm{Ca}$ \\
\hline & variable & & $\begin{array}{l}\text { variable } \mathrm{Zn} \\
+\mathrm{CaSO}_{4} \\
\text { particles }\end{array}$ & & $\begin{array}{l}\text { variable } \mathrm{Zn} \\
+\mathrm{CaSO}_{4} \\
\text { particles }\end{array}$ & \\
\hline \multirow[t]{6}{*}{2} & $9-11 \%$ & $\mathrm{Si}$ & $10-15 \%$ & $\mathrm{Ca}$ & $20 \%$ & $\mathrm{Ca}$ \\
\hline & $8-10 \%$ & $\mathrm{Fe}$ & $8-10 \%$ & $\mathrm{Fe}$ & $1-2 \%$ & $\mathrm{Al}$ \\
\hline & $6-8 \%$ & $\mathrm{Al}$ & $2-4 \%$ & $\mathrm{Al}$ & $1-2 \%$ & $\mathrm{Fe}$ \\
\hline & $6-7 \%$ & $\mathrm{Ca}$ & $1-4 \%$ & $\mathrm{~S}$ & $1-2 \%$ & $\mathrm{Si}$ \\
\hline & $0 \%$ & $S$ & $1-4 \%$ & $\mathrm{Si}$ & $0.50 \%$ & $S$ \\
\hline & $\begin{array}{l}+\mathrm{CaO} / \\
\mathrm{Ca}(\mathrm{OH})_{2} \\
\text { particles }\end{array}$ & & $\begin{array}{l}+\mathrm{CaSO}_{4} \\
\text { particles }\end{array}$ & & & \\
\hline \multirow[t]{5}{*}{3} & $13-17 \%$ & $\mathrm{Ca}$ & $15-20 \%$ & $\mathrm{Ca}$ & $20-25 \%$ & $\mathrm{Ca}$ \\
\hline & $3-4 \%$ & $\mathrm{Fe}$ & $0-2 \%$ & $\mathrm{Al}$ & $0-2 \%$ & S \\
\hline & $2-4 \%$ & $\mathrm{Si}$ & $0-2 \%$ & $\mathrm{Si}$ & $0-1 \%$ & $\mathrm{Si}$ \\
\hline & $2-3 \%$ & $\mathrm{Al}$ & $0-1 \%$ & S & $0-1 \%$ & $\mathrm{Fe}$ \\
\hline & $<0.5 \%$ & $S$ & $\begin{array}{l}0-1 \% \\
+\mathrm{CaSO}_{4} \\
\text { particles }\end{array}$ & $\mathrm{Fe}$ & $\begin{array}{l}0.50 \% \\
+\mathrm{CaSO}_{4} \\
\text { particles }\end{array}$ & $\mathrm{Al}$ \\
\hline
\end{tabular}

confirm that location in the flow pattern did not appreciably affect scale build up in the samples.

To measures sample weight change, samples were dried for $2 \mathrm{~h}$ at $50^{\circ} \mathrm{C}$, and then an OHaus Explorer
EX423 balance (Parsippany, NJ) was used (readability of $1 \mathrm{mg}$ ). Weight change results were normalized by sample surface area and total exposure time, and are reported as $\mu \mathrm{g} / \mathrm{mm}^{2}$-week. To examine surface morphology and determine elemental composition, scanning electron microscopy with energy dispersive x-ray (SEM-EDX) was performed. All work was done using a FEI Quanta 600 FEG environmental SEM (Hillsboro, OR) equipped with a Bruker Quantax 400 EDX spectroscope (Ewing, NJ).

\section{Results and discussion}

\section{1. wt change}

Photos displaying representative samples from each exposure location in each reservoir are shown in Fig. 2 at three, nine and 16 weeks of exposure. Fig. 3 summarizes the weight change results.

There are four main bases for the comparison of sample weight changes: between the different water qualities (i.e., Reservoirs 1-3), the location of the sample exposure within a reservoir (i.e., sides, bottom, or tube), the exposure time (i.e., three, nine or 16 weeks), and the sample materials (i.e., lined versus traditional $\mathrm{PE}$ ).

From Fig. 3, it is clear that the rate of scale buildup tended to decrease over time for almost all

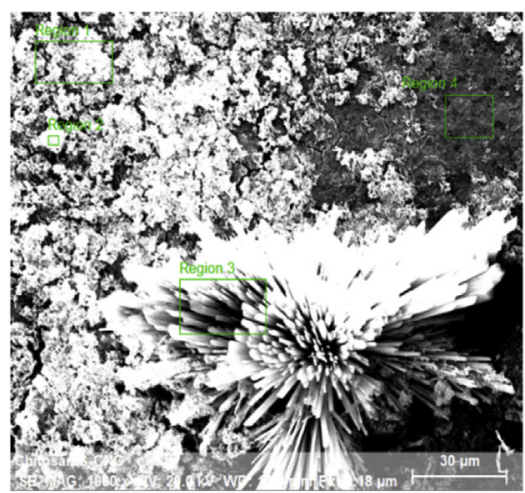

Atomic percent (\%)

$\begin{array}{lrrrrrrr}\text { Spectrum } & \text { O } & \text { Al } & \text { Si } & \text { S } & \text { Ca } & \text { Fe } & \text { Zn } \\ \text { Region 1 } & 58.83 & 9.46 & 5.01 & 3.85 & 0.31 & 19.34 & 3.19 \\ \text { Region 2 } & 58.19 & 11.63 & 5.79 & 3.96 & 0.25 & 17.49 & 2.70 \\ \text { Region 3 } & 60.98 & 0.09 & 0.09 & 14.46 & 23.92 & 0.40 & 0.05 \\ \text { Region 4 } & 60.75 & 10.97 & 7.36 & 3.84 & 1.36 & 14.43 & 1.28\end{array}$

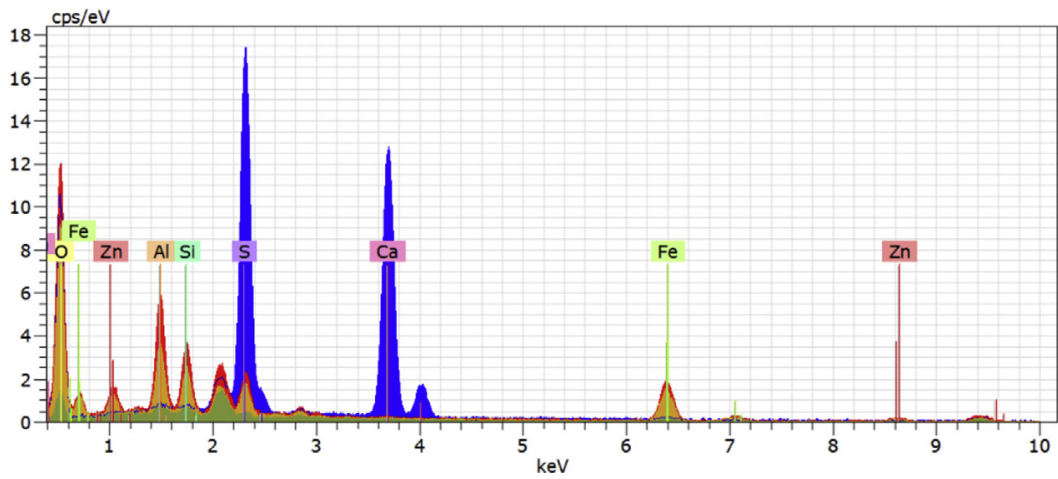

Region 1

Region 2

Region 3

Region 4

Fig. 5. Example spectra from scale buildup on a sample mounted to the side of Reservoir 1. Image captured at 1000x magnification. 


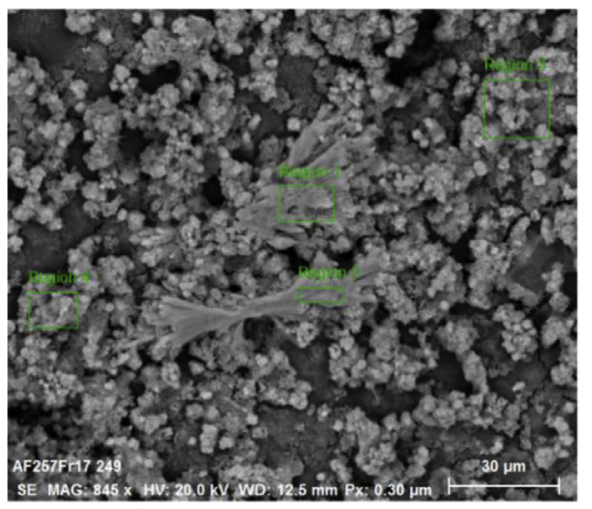

Atomic percent (\%)

$\begin{array}{lrrrrrrr}\text { Spectrum } & \text { O } & \text { Na } & \text { Al } & \text { Si } & \text { S } & \text { Ca } & \text { Fe } \\ \text { - } & & & \\ \text { Region } 1 & 74.37 & 0.53 & 0.73 & 0.60 & 10.09 & 13.25 & 0.44 \\ \text { Region } 2 & 70.67 & 0.26 & 0.27 & 0.30 & 10.52 & 17.53 & 0.46 \\ \text { Region } 3 & 75.79 & 2.45 & 3.31 & 3.06 & 0.57 & 11.98 & 2.84 \\ \text { Region } 4 & 76.40 & 1.63 & 2.14 & 1.49 & 0.42 & 16.84 & 1.09\end{array}$

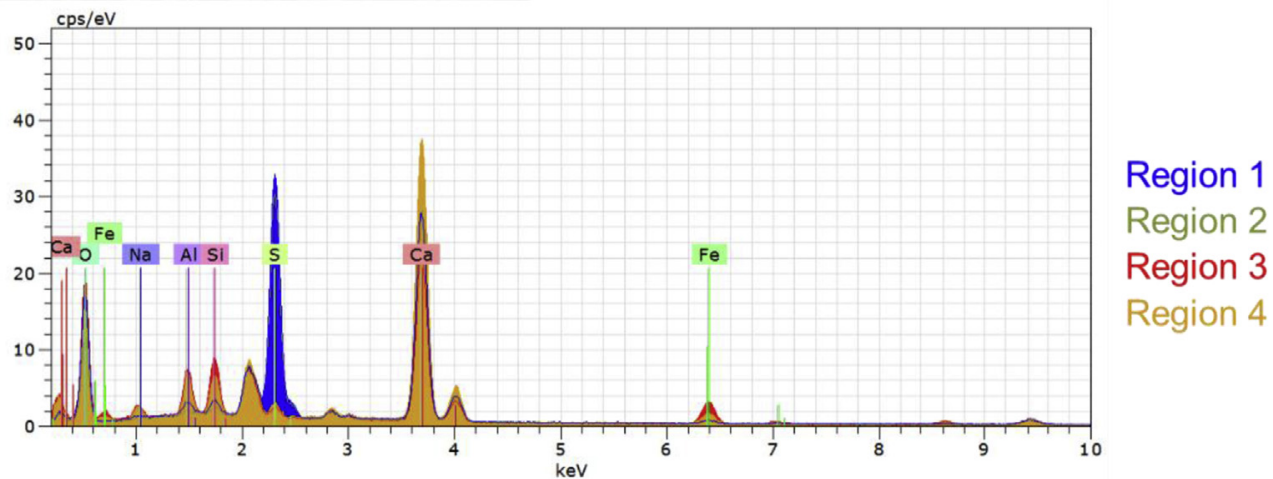

Fig. 6. Example spectra from scale buildup on a sample mounted to the side of Reservoir 2. Image captured at 850x magnification.

conditions. This is somewhat surprising, since scaling is often observed to accelerate once initiated [25]. In the current study, one possible explanation is that early scale accumulation was present in physically unstable structures (e.g., only weakly adhered to the sample surface or with significant porosity). In this case, some detachment could have occurred due to water flow or other disturbances.

Fig. 3 further illustrates that water quality and exposure location also affected scale buildup on both materials. Overall, the low $\mathrm{pH}$ condition (Reservoir 1) tended to produce less scale buildup than the higher $\mathrm{pH}$ conditions (Reservoirs 2 and 3), which behaved more similarly. However, it is notable that the rate of buildup after nine weeks was similar across all three water qualities for samples exposed to constant flow in the pipe-loop tubes. Mechanisms of scale buildup on these samples could have included particle settling, as well as diffusion and attachment of small particles and precipitation of solids directly onto the sample surfaces. Similar mechanisms are expected for the samples located on the bottom of the reservoirs, although the samples on the bottom of Reservoir 1 exhibited lower scale buildup rates than their counterparts in Reservoirs 2 and 3. This might be due to different flow effects (e.g., turbulent flow in the pipe-loops versus gentle mixing around the reservoir bottom), which could have resulted in different diffusion rates of ions or small particles to the sample surfaces.

The side-mounted samples had the smallest rates of scale buildup across all water qualities, with the low $\mathrm{pH}$ condition consistently producing very little scale. Unlike the tube and bottom samples, these samples were not subject particle settling and could have only gained weight due to diffusion and direct precipitation. In Fig. 2, it can be seen that the scale formed in small patches on these samples.

Despite trends observed between water qualities, exposure locations and with exposure time, only marginal differences in the rate of scale buildup could be observed for lined versus traditional PE material - and these were generally not statistically significant (i.e., compare the $95 \%$ confidence limits shown for side- and bottom-mounted samples in Fig. 3). This finding fits with observations from the earlier field study of the same lined and traditional PE materials tested [24], which also found that neither material consistently gained more weight than the other.

\subsection{SEM results}

SEM was used to examine the morphology and chemical makeup of mineral scales (using EDX) that 


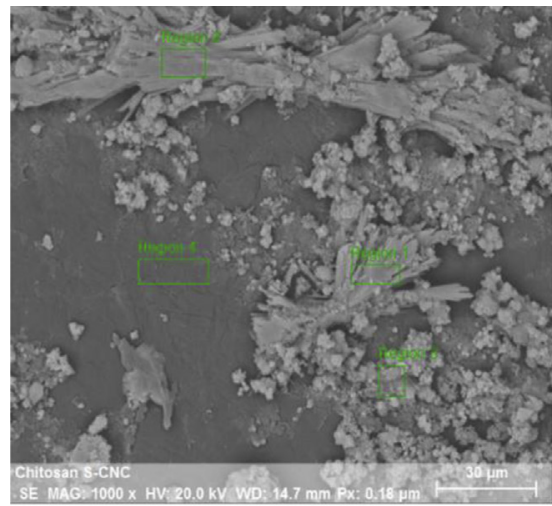

Atomic percent $(\%)$

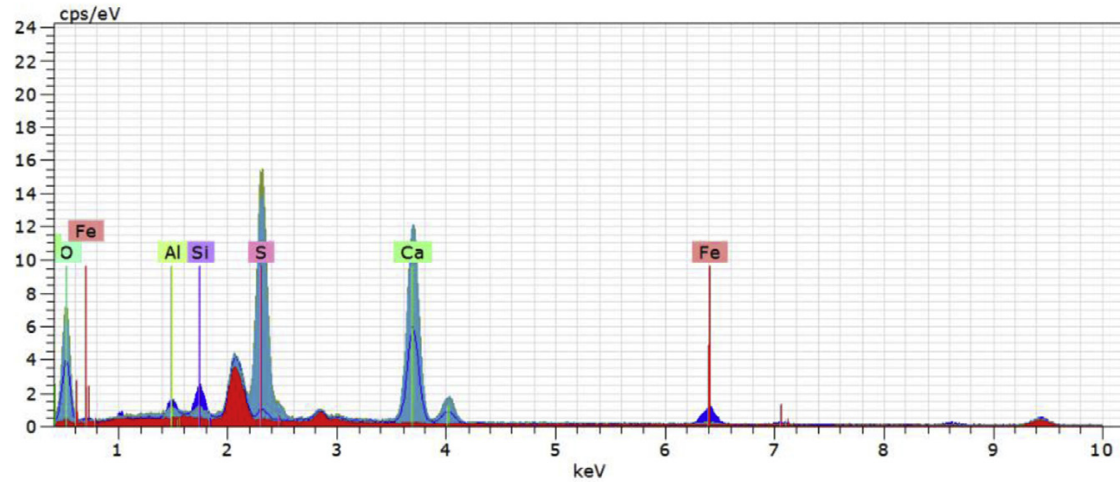

Region 1

Region 2

Region 3

Region 4

Fig. 7. Example spectra from scale buildup on a sample mounted to the side of Reservoir 3. Image captured at 1000x magnification.

built up on the pipe samples. Again, in keeping with observations from the previous field study [24], no real differences were found between the two materials. However, notable differences could be seen based on water quality and sample exposure location within the test apparatus.

Scale morphology tended to vary most noticeably between the three exposure locations (Fig. 4). The samples exposed in the pipe-loop tubes showed the most similar morphologies across all water qualities. Finely grained scale appeared in large (over $100 \mu \mathrm{m}$ length) patches with very few distinguishable particles. This morphology indicates that diffusion likely played a key role in the scale buildup on these samples. Scale which precipitates or forms due to settled particles would likely be larger, and less uniform in size. The scale cracking visible in Fig. 4 developed as the samples dried prior to analysis.

The side-mounted samples exposed to all three water qualities exhibited $10-100 \mu \mathrm{m}$ diameter euhedral crystals of calcium sulfate. More of these particles were present in the samples exposed to higher $\mathrm{pH}$ conditions (Reservoirs 2 and 3) than those from the low $\mathrm{pH}$ condition (Reservoir 1). Given that calcium sulfate, which was used to dose calcium to the test waters, is relatively insoluble, it seems likely that these particles were present due to the water recipe and simply diffused to the pipe samples. The bottom-mounted samples exhibited a similar morphology to the side samples, though they generally had higher total mass of scale.

Regardless of exposure location or water quality, the SEM analysis showed morphologically similar scales with increasing exposure time. That is, all else being equal with respect to the water quality and sample exposure location, the scale buildup only appeared to vary by total mass.

While scale morphology varied mostly by exposure location, chemical composition varied mostly by water quality (Table 2). Scale on samples from the low $\mathrm{pH}$ condition (Reservoir 1) was dominated by iron and aluminum, which is consistent with expectations [26]. Dissolved forms of these elements were not abundant in the test water (Table 1), which suggests they very quickly formed insoluble hydroxides that were incorporated into the scale. The low $\mathrm{pH}$ condition also produced relatively high sulfur content in the scale buildup, but relatively low calcium - aside from the calcium sulfate particles noted above. In the higher $\mathrm{pH}$ conditions (Reservoirs 2 and 3), scales became more abundant in calcium. This is consistent with expectations for scaling due to precipitation $[27,28]$.

Aside from major changes in scale composition with water quality, Table 2 does indicate some notable differences with sample exposure location. 


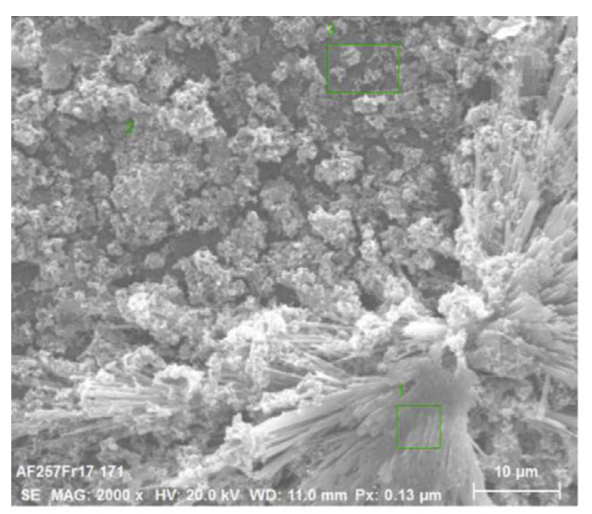

Atomic percent (\%)

\begin{tabular}{lrrrrrr} 
Spectrum & 0 & Al & Si & S & Ca & Fe \\
\hdashline 1 & 72.38 & 0.57 & 0.14 & 12.08 & 14.43 & 0.40 \\
2 & 71.20 & 7.37 & 3.48 & 2.28 & 0.00 & 15.67 \\
3 & 73.19 & 9.57 & 4.17 & 2.47 & 0.00 & 10.60
\end{tabular}

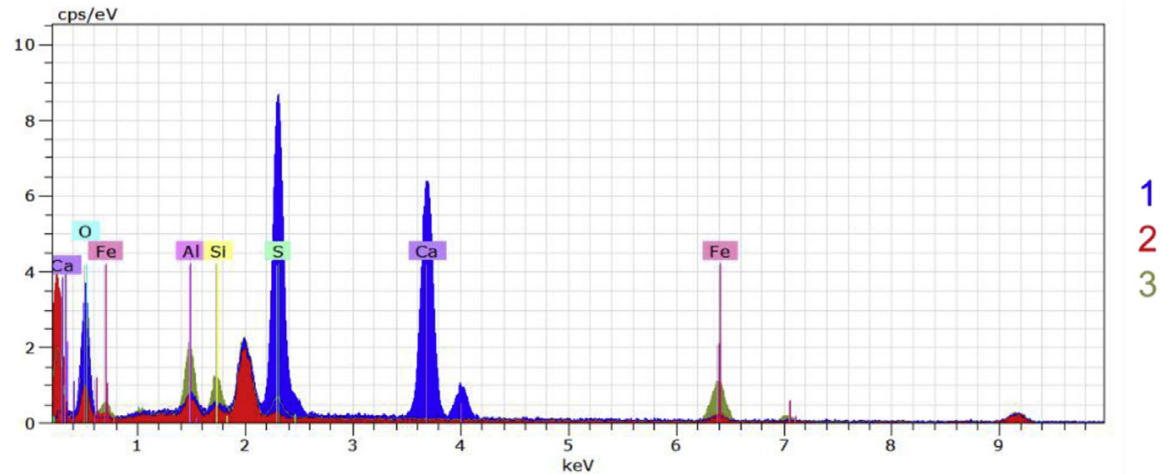

Fig. 8. Example spectra from scale buildup on a sample mounted to the bottom of Reservoir 1. Image captured at 2000x magnification.

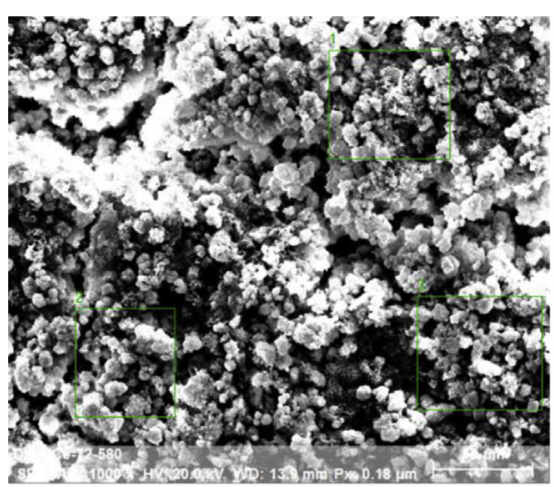

$\begin{array}{lccccccc}\begin{array}{l}\text { Atomic percent }\left(\frac{\circ}{6}\right) \\ \text { Spectrum }\end{array} & & & & & & & \\ -1 & \mathrm{Al} & \mathrm{Si} & \mathrm{S} & \mathrm{Ca} & \mathrm{Fe} & \mathrm{Zn} \\ 1 & 75.11 & 0.98 & 0.84 & 0.49 & 20.63 & 1.47 & 0.48 \\ 2 & 74.16 & 1.47 & 1.22 & 0.59 & 19.96 & 2.00 & 0.60 \\ 3 & 71.35 & 1.35 & 1.25 & 0.51 & 22.66 & 2.43 & 0.45\end{array}$

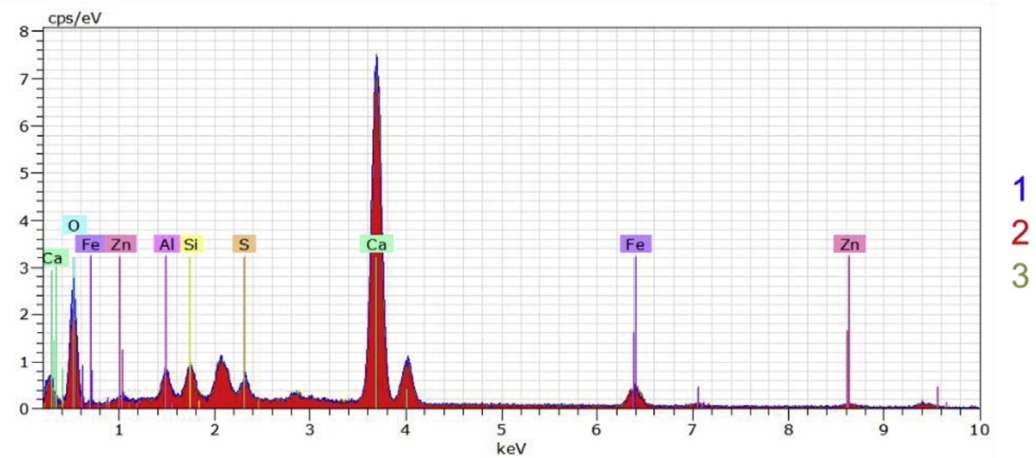

Fig. 9. Example spectra from scale buildup on a sample mounted to the bottom of Reservoir 2. Image captured at 1000x magnification. 


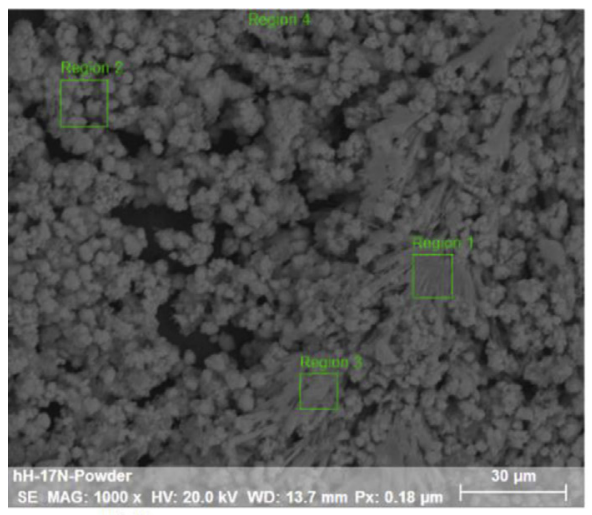

\begin{tabular}{|c|c|c|c|c|c|c|}
\hline Spectrum & O & Al & $\mathrm{Si}$ & S & $\mathrm{Ca}$ & $\mathrm{Fe}$ \\
\hline n 1 & 77.38 & 0.05 & 0.03 & 8.20 & 14.24 & 0.11 \\
\hline egion 2 & 76.28 & 0.40 & 0.43 & 0.55 & 21.82 & 0.53 \\
\hline egion 3 & 73.07 & 0.67 & 0.71 & 9.30 & 15.62 & 0.62 \\
\hline gion 4 & 73.08 & 0.29 & 0.37 & 1.54 & 24.23 & 0.4 \\
\hline
\end{tabular}

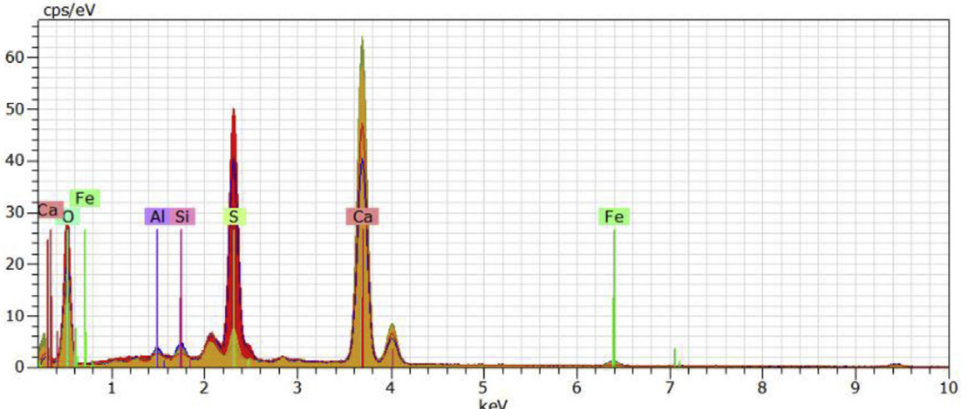

Region 1

Region 2

Region 3

Region 4

Fig. 10. Example spectra from scale buildup on a sample mounted to the bottom of Reservoir 3. Image captured at 1000x magnification.

For instance, in Reservoirs 2 and 3, the samples exposed in the pipe-loop tubes tended to have higher iron and/or aluminum, and lower calcium, than the other samples in the same reservoir; and these differences were more pronounced between the tube and bottom-mounted samples. Such observations further suggest different scaling mechanisms between the exposure locations.

Figs. 5-13 show representative images and associated EDX spectra for each unique combination of

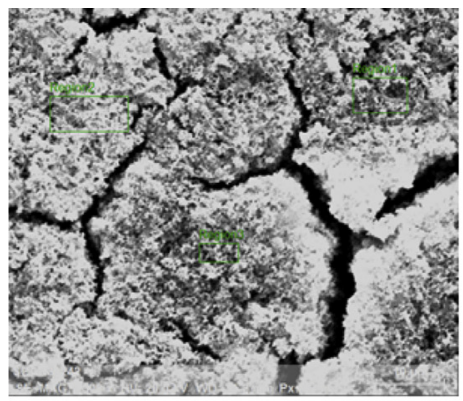

\begin{tabular}{|c|c|c|c|c|c|c|}
\hline spectrum & $\mathrm{O}$ & Al & Si & $S$ & $\mathrm{Ca}$ & $\mathrm{Fe}$ \\
\hline Region1 & 62.80 & 9.19 & 4.52 & 2.35 & 0.57 & 20.58 \\
\hline Region2 & 63.86 & 9.86 & 4.88 & 2.37 & 0.60 & 18.43 \\
\hline Region3 & 62.49 & 9.52 & 4.65 & 2.42 & 0.65 & 20.26 \\
\hline
\end{tabular}

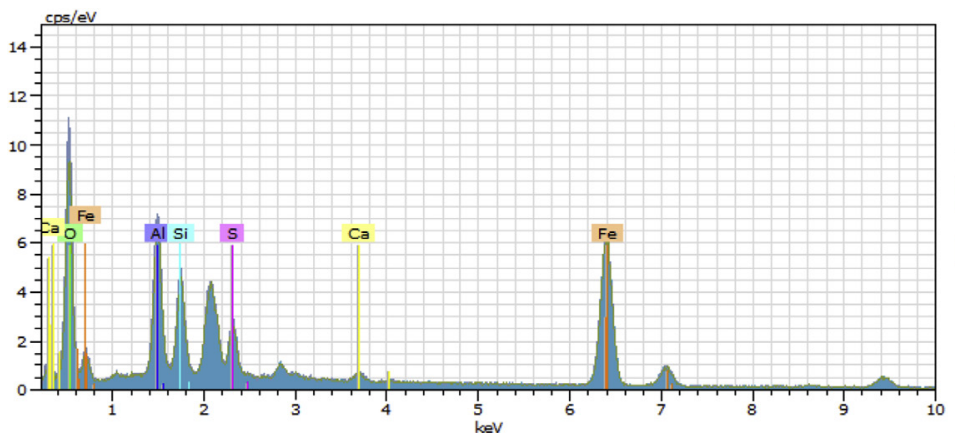

\section{Region1 \\ Region2 Region3}

Fig. 11. Example spectra from scale buildup on a sample mounted within the pipe-loop of Reservoir 1. Image captured at $2000 x$ magnification. 


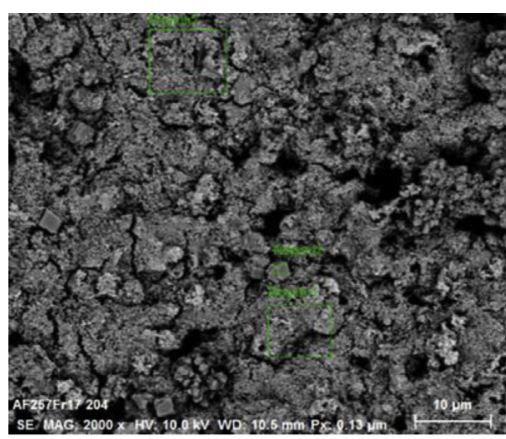

Atomic percent (\%)

\begin{tabular}{|c|c|c|c|c|c|c|c|}
\hline Spectrum & 0 & Al & $\mathrm{Si}$ & $\mathrm{S}$ & $\mathrm{Ca}$ & $\mathrm{Fe}$ & $\mathrm{Zn}$ \\
\hline Region1 & 65.75 & 6.55 & 9.27 & 0.00 & 6.42 & 10.08 & 1.9 \\
\hline Region2 & 78.68 & 0.32 & 0.00 & 0.46 & 20.53 & 0.00 & 0.00 \\
\hline egion3 & 64.68 & 7.22 & 11.21 & 0.00 & 6.13 & 8.46 & 2.30 \\
\hline
\end{tabular}

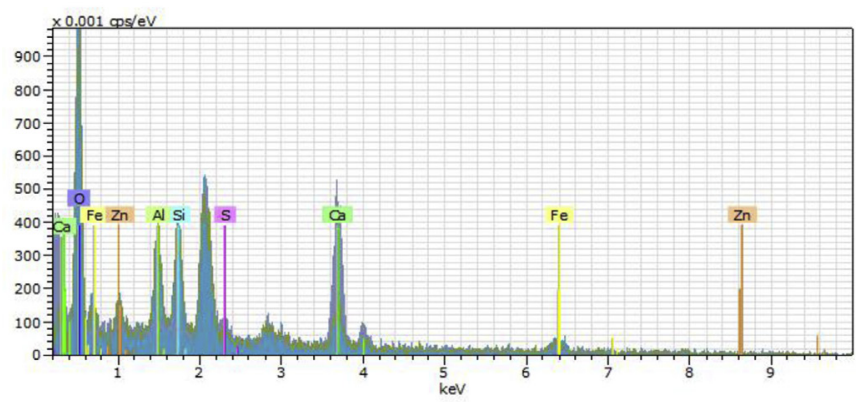

Region1

Region 2

Region 3

Fig. 12. Example spectra from scale buildup on a sample mounted within the pipe-loop of Reservoir 2. Image captured at 2000x magnification.

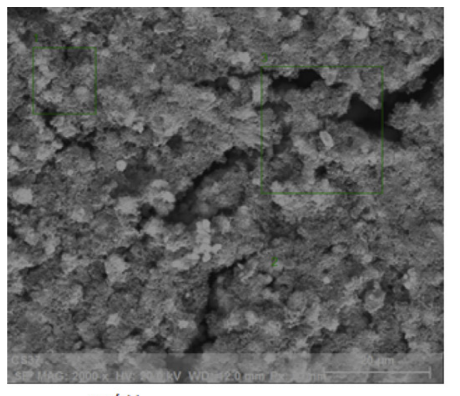

Atomic percent (\%)

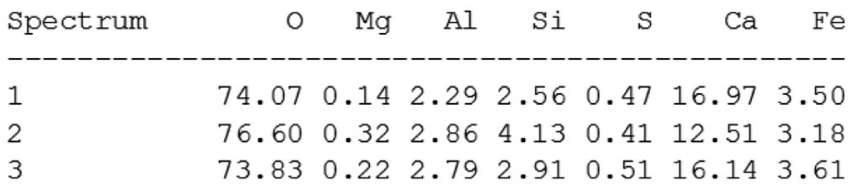

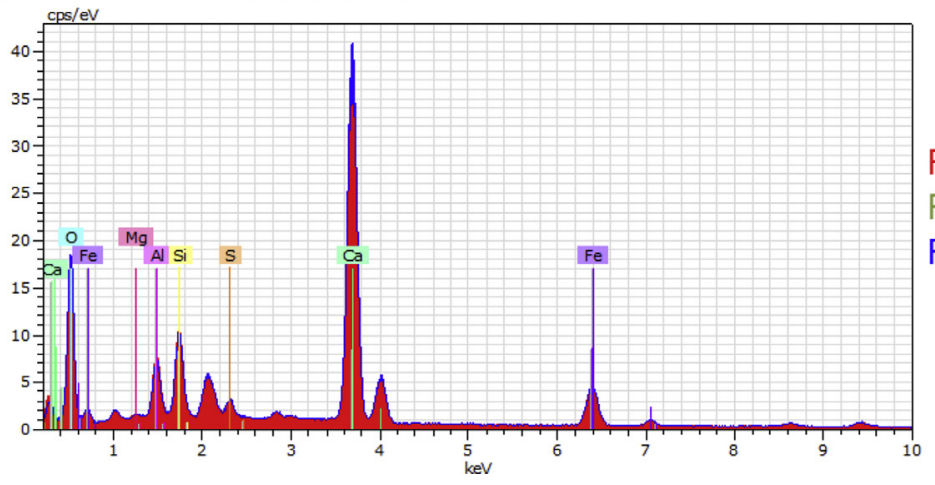

Region 1

Region 2

Region 3

Fig. 13. Example spectra from scale buildup on a sample mounted within the pipe-loop of Reservoir 3. Image captured at 2000x magnification.

water quality and sample exposure location. These figures more clearly illustrate the morphology of different scale components (e.g., large particles of calcium sulfate versus finer grained mixed scales); and indicate buildup mechanisms (e.g., thin layers of precipitates on side-mounted samples versus thicker layers of scale due to precipitation and settling on bottom-mounted samples).

\section{Conclusions}

Rubber-based liners have been considered to enhance PE pipe performance against abrasion. However, to determine if such liners may be a candidate for widespread use in mining applications, the performance of the liner against other common problems that affect piping systems must 
also be evaluated. One such problem is the issue of scale buildup on pipe surfaces. In this laboratory study, a lined PE material was tested against traditional PE to determine the relative susceptibility to scale buildup under three idealized AMD conditions.

The scale buildup rate, morphology and chemical composition varied across the water quality conditions and sample exposure locations. Specifically, the lowest $\mathrm{pH}$ condition had the least amount of scale, which was dominated by iron hydroxides. Moderate and high $\mathrm{pH}$ conditions had more similar scales, which were dominated by calcium minerals. Samples exposed to continuous flow in these experiments had the greatest weight gain, consistent with scale buildup due to settling, precipitation, and diffusion. Across all the conditions tested here, scale buildup occurred over the entire test period, but the growth rate appeared to slow and become limited over time; this may have been due to a weak scale structure which allowed material to detach at times. Most importantly, consistent differences were not observed between the lined and traditional PE samples with respect to scale buildup rate. Furthermore, SEM analysis showed very similar scale morphology between the two materials. As such, if the liner performs significantly better than the traditional PE with regards to abrasion, it might be a good candidate for MIW applications.

\section{Conflicts of interest}

None declared.

\section{Ethical statement}

Authors state that the research was conducted according to ethical standards.

\section{Funding body}

This work was partially funded by the SME Foundation (via a Career Development Grant to Emily Sarver).

\section{Acknowledgements}

The authors would like to thank Steve McCartney and Chris Winkler of the Virginia Tech ICTASNCFL for assistance with SEM work, and Jeff Parks of the Via Department of Civil and Environmental Engineering at Virginia Tech for assistance with ICP analysis. Further, we thank Gerodur MPM Kunststoffverarbeitung $\mathrm{GmbH}$ and $\mathrm{Co}$. KG. for supplying the pipe materials tested here. The views expressed here are those of the authors and do not necessarily represent views of funding sources or research partners.

\section{References}

[1] Lottermoser B. Mine wastes characterization, treatment and environmental impacts. Springer Berlin Heidelberg; 2003.

[2] Fourie A, Bouazza A, Lupo J, Abrão P. Improving the performance of mining infrastructure through the judicious use of geosynthetics. In: 9th international conference on geosynthetics; 2010.

[3] Mandrone G. An ultrasonic prototype to remedy pipes clogging. Bulletin Engin Geo Environ 2015;75(2):673-80. https://doi.org/10.1007/s10064-015-0833-7.

[4] Runtti H, Tolonen ET, Tuomikoski S, Luukkonen T, Lassi U. How to tackle the stringent sulfate removal requirements in mine WaterTreatment-a review of potential methods. Environ Res 2018;167:207-22. https://doi.org/10.1016/j.envres. 2018.

[5] Singer P, Stumm W. Acidic mine drainage: The rate-determining step. Science 1970;167(3921):1121-3. Retrieved from, http://www.jstor.org.ezproxy.lib.vt.edu/stable/1728684.

[6] McLemore VT, editor. Basics of metal mining influenced water, Vol. 1. The Society for Mining, Metallurgy, and Exploration, Inc; 2008.

[7] Nordstrom DK. Mine waters: Acidic to circmneutral. Elements 2011;7(6):393-8. https://doi.org/10.2113/gselements.7. 6.393.

[8] Cherry D, Currie R, Soucek D, Latimer H, Trent G. An integrative assessment of awatershed impacted by abandoned mined land discharges. Environ Pollu 2001;111(3): 377-88. https://doi.org/10.1016/s0269-7491(00)00093-2.

[9] Cravotta CA, Brady KBC. Priority pollutants and associated constituents in untreated and treated discharges from coal mining or processing facilities in Pennsylvania. USA Appl. Geochem. 2015. https://doi.org/10.1016/j.apgeochem.2015.03. 001.

[10] Gross W. Ecophysiology of algae living in highly acidic environments. Hydrobiologia 2000;433(1-3):31-7.

[11] Olõas M, Nieto J, Sarmiento A, Cerón J, Cánovas C. Seasonal water quality variations ina river affected by acid mine drainage: The odiel river (south west Spain). Sci Tot Environ 2004;333(1-3):267-81. https://doi.org/10.1016/j.scitotenv. 2004.05.012.

[12] Younger Paul L, Wolkersdorfer C. Mining impacts on the fresh water environment: Technical and managerial guidelines for catchment scale management. Mine Water Environ 2004;23(S1). https://doi.org/10.1007/s10230-004-0028-0.

[13] Zhao JQ, Ju HY, Li JH. Corrosion mechanism of similar soil slope corroded by AcidMine drainage and its reinforcing treatments in metal mines. Appl Mechan Mat 2011;90-93: 597-600. https://doi.org/10.4028/www.scientific.net/amm.9093.597.

[14] Younger PL, Banwart SA, Hedin RS. Mine water: Hydrology, pollution, remediation. New York, NY: Springer Publishing; 2002.

[15] Skousen J, Zipper C, Rose A, Ziemkiewicz PF, Nairn R, McDonald LM, et al. Review of passive systems for acid mine drainage treatment. Mine Water Environ 2016;36:133-53. https://doi.org/10.1002/9781118749197.ch30.

[16] Taylor J, Pape S, Murphy N. A summary of passive and active treatment technologies forAcid and metalliferous drainage (AMD). 2005.

[17] Hengen TJ, Squallice MK, O'Sullivan AD, Stone JJ. Life cycle assessment analysis ofactive and passive acid mine drainage treatment technologies. Res Cons Recycl 2014;86:160-7.

[18] Rakotonimaro TV, Neculita CM, Bussière B, Benzaazoua $M$, Zagury GJ. Recoveryand reuse of sludge from active and passive treatment of mine drainage-impacted waters: Areview. Environ Sci Pollu Res 2017;24(1):73-91. https://doi.org/ 10.1007/s11356-0167733-7. 
[19] Al TA, Martin CJ, Blowes DW. Carbonate-mineral/water interactions in sulfide-rich mine tailings. Geochimica et Cosmochimica Acta 2000;64(23):3933-48. https://doi.org/ 10.1016/s00167037(00)00483-x.

[20] Watzlaf GR, Schroeder KT, Kairies CL. Long-term performance of anoxic limestonedrains. Mine Water Environ 2000; 19(2):98-110. https://doi.org/10.1007/bf02687258.

[21] Campbell K, Alpers C, Nordstrom D, Blum A, Williams A. Characterization and remediation of iron(III) oxide-rich scale in a pipeline carrying acid mine drainage at iron mountain mine, California, USA. Geomicrob J 2013;34(3):193-206. https://doi.org/10.1080/01490451.2016. 1155679.

[22] Rötting TS, Thomas RC, Ayora C, Carrera J. Passive treatment of acid mine drainage with high metal concentrations using dispersed alkaline substrate. J Environ Qual 2008;37(5): 1741. https://doi.org/10.2134/jeq2007.0517.

[23] DeCou G, Davies P. Evaluation of abrasion resistance of pipe and pipe lining materials. California Department of Transportation; 2007.
[24] Pezzuto A, Sarver EA, Mischo H. A field study OF mineral scale buildup ON lined ANDTRADITIONAL PE water pipes. In: Proceedings of the 2017 SME annual conference and expo (paper 17-139). Denver, CO; 2017.

[25] Muryanto S, Bayuseno A, Ma'Mun H, Usamah M, Jotho. Calcium carbonate ScaleFormation in pipes: Effect of flow rates, temperature, and malic acid as additives on the massand morphology of the scale. Pro Chem 2014;9:69-76. https://doi.org/10.1016/j.proche.2014.05.009.

[26] Balintova M, Petrilakova A. Study of $\mathrm{pH}$ influence on selective precipitation of heavy metals from acid mine drainage. Chem Engin Trans 2011;25. https://doi.org/10.3303/ CET1125058.

[27] Chilingar GV, Al-Qahtani G, Mourhatch R. The fundamentals of corrosion and scaling forpetroleum and environmental engineers. Houston: Gulf Publishing Company; 2008

[28] Mackie AL, Walsh Margaret E. Bench-scale study of active mine water treatment using cement kiln dust (CKD) as a neutralization agent. Water Res 2012;46(2):327-34. https:// doi.org/10.1016/j.watres.2011.10.030. 